\title{
Use of MALDI-TOF to characterize staphylococcal intramammary infections in dairy goats
}

\author{
Véronique Bernier Gosselin, ${ }^{*}$ Jessica Lovstad, ${ }^{*}$ Simon Dufour,†‡ Pamela R. F. Adkins, ${ }^{*}$ \\ and John R. Middleton*1 \\ *Department of Veterinary Medicine and Surgery, College of Veterinary Medicine, University of Missouri, 900 East Campus Dr., Columbia 65211 \\ †Department of Pathology and Microbiology, Faculty of Veterinary Medicine, Université de Montréal, 3200 Sicotte, Saint-Hyacinthe, QC, Canada, \\ J2S $2 \mathrm{M} 2$ \\ ‡Canadian Bovine Mastitis and Milk Quality Research Network, 3200 Sicotte, Saint-Hyacinthe, QC, Canada, J2S 2M2
}

\begin{abstract}
The most common pathogens causing intramammary infections (IMI) in dairy goats are staphylococci. Gene sequencing has been the reference method for identification of staphylococcal species, but MALDITOF mass spectrometry could represent a rapid and cost-effective alternative method. The objectives were to evaluate the typeability and accuracy of partial gene sequencing and MALDI-TOF for identifying staphylococci isolated from caprine milk samples, and to evaluate the relationship between staphylococcal species IMI, milk somatic cell score (SCS), and milk yield (MY). A composite (goat-level) milk sample was collected from all 940 lactating goats in a single herd. Dairy Herd Information Association test-day data for parity, days in milk, SCS, and MY were retrieved from Dairy Herd Information Association records. Milk samples were cultured on Columbia blood agar, and isolates from samples that yielded a single colony type of a presumptively identified Staphylococcus spp. were identified by PCR amplification and partial sequencing of rpoB, tuf, or 16S-rRNA, and MALDI-TOF. Mixed linear models were used to evaluate the relationship between staphylococcal IMI, SCS, and MY. The goat-level prevalence of staphylococcal IMI based on isolation of a single colony type was $24.4 \%$ (213/874). Seventeen goats had a contaminated sample. Among the remaining goats $(\mathrm{n}=857)$, the most common species causing single colony-type IMI were Staphylococcus simulans (7.9\%), Staphylococcus xylosus (3.5\%), Staphylococcus caprae (3.6\%), Staphylococcus chromogenes $(2.9 \%)$, and Staphylococcus epidermidis (2.2\%). The typeability of staphylococcal isolates with partial housekeeping gene sequence analysis (rpoB, complemented by tuf and $16 \mathrm{~S}$ as needed) was $97.7 \%$. The typeability and accuracy of
\end{abstract}

Received November 30, 2017

Accepted March 20, 2018

${ }^{1}$ Corresponding author: middletonjr@missouri.edu
MALDI-TOF were 84 and 100\%, respectively. Overall, only Staphylococcus chromogenes IMI was associated with a higher SCS than goats with no growth. After adjusting for parity and stage of lactation, staphylococcal IMI status was not significantly associated with MY. For the staphylococci isolated from goats in this herd, MALDI-TOF proved an accurate method of speciation with a relatively high typeability. An association between staphylococcal IMI, SCS, and MY was not defined using goat-level data with the exception of S. chromogenes IMI, which was associated with a higher SCS than goats with no growth.

Key words: caprine, mastitis, subclinical, staphylococci

\section{INTRODUCTION}

In dairy goats, mastitis resulting from IMI is, for the most part, subclinical. Prevalence of IMI in goats has been reported by investigators from various countries around the world, and estimates range from 20 to $47 \%$ of goats (Contreras et al., 2003). Subclinical mastitis can cause microscopic or biochemical changes in milk and decreased milk production (Leitner et al., 2004b; Koop et al., 2010). The most common bacteria isolated from cases of subclinical mastitis are staphylococci, including Staphylococcus aureus and the non-aureus Staphylococcus spp. (NAS) with NAS IMI being much more prevalent than $S$. aureus IMI (Bergonier et al., 2003; Contreras et al., 2003). In cows, NAS IMI tends to cause a mild to moderate increase in SCC, and this effect can vary between NAS species (Fry et al., 2014). However, in goats, the relationship between NAS infection, SCC, and milk loss is less clear (Koop et al., 2010). Somatic cell count in goats is influenced by factors other than bacterial infection, including parity, stage of lactation, and caprine arthritis-encephalitis virus infection (Paape and Capuco, 1997). Studies on the pathogenicity of different NAS species in goats have yielded conflicting results, which could be explained by the presence of confounding factors affecting SCC and 
the variability in the presence and relative prevalence of different NAS species between herds and studies (Contreras et al., 1995). In contrast, although $S$. aureus is less prevalent than NAS, it is considered a major mastitis pathogen due to its association with clinical mastitis and increased SCC (Deinhofer and Pernthaner, 1995; Contreras et al., 2003; Koop et al., 2012b).

To study differences in pathogenicity between staphylococcal species, accurate species identification methods are required. Several NAS species in goats are difficult to identify by phenotypic methods alone, yielding poor typeability; hence, genotypic methods are considered more reliable (Koop et al., 2012a; Onni et al., 2012). Sequencing of housekeeping genes or the whole genome is considered the reference method for identification of staphylococcal species (Zadoks and Watts, 2009). Gene-based identification methods and other molecular-based techniques rely on the availability of a database, and typeability and accuracy are affected by the origin of the isolates used to build the database. Polymerase chain reaction RFLP analysis of the staphylococcal groEL gene (Onni et al., 2012), and transfer RNA-intergenic spacer PCR supplemented with gene sequence analysis were previously reported to have good accuracy and typeability for identification of NAS isolated from goat milk (McDougall et al., 2010; Koop et al., 2012b). Another rapid, cost-effective molecular method and potential alternative to gene sequencing is MALDI-TOF MS. The typeability of NAS isolates from cow milk with MALDI-TOF, using a score $\geq 2.0$ for species identification, ranged from 63.7 to $95.4 \%$, and accuracy ranged from 96 to $100 \%$ when compared with PCR-RFLP or gene sequence analysis (Tomazi et al., 2014; Cameron et al., 2017, 2018). However, similar data evaluating staphyloccoci isolated from goat milk are absent.

The objectives of the study reported here were to (1) evaluate the typeability of staphylococcal isolates from goat milk using partial gene sequence analysis and MALDI-TOF, as well as the accuracy of species identification by MALDI-TOF using partial gene sequence analysis as a reference method, and (2) evaluate the relationship between staphylococcal IMI status, SCS, and milk yield (MY), after adjusting for parity and stage of lactation.

\section{MATERIALS AND METHODS}

\section{Study Population}

The dairy operation selected for the study was located in northeast Missouri. At the time of the study, the herd was composed of approximately 940 lactating mixed breed dairy goats, with a predominance of Saanen and some Alpine, Toggenburg, and La Mancha lineages; the specific lineage of each goat was unknown. Goats were housed in 4 different pens with a range of 175 to 276 goats per pen. The dairy was in year-round production. Annual MY per goat was reported by the farm to be approximately $900 \mathrm{~kg}$. The goats were machine-milked twice daily in a milking parlor. Premilking and postmilking teat disinfection using iodine-based products was practiced, and milking personnel wore disposable nitrile gloves during milking. No antimicrobials were used to treat cases of clinical or subclinical mastitis. Cases of clinical mastitis that did not spontaneously cure were culled.

\section{Sampling}

This study was approved by the University of Missouri Animal Care and Use Committee. The study design was an observational cross-sectional study. A single sampling was conducted on all milking goats just before the morning milking, $2 \mathrm{~d}$ after the monthly DHIA test. Goat-level data for parity, DIM, SCC, and MY on the test day were retrieved from DHIA records. The DHIA collects milk for SCC into nonsterile vials containing a 2-bromo-2-nitropropane-1, 3-diol preservative tablet (Broad Spectrum Microtabs II, D \& F Control Systems Inc., Dublin, CA) using an in-line sampler. Samples for milk SCC enumeration were analyzed by a commercial laboratory (Mid-South Dairy Records, Springfield, MO) using an automated counter (Bentley Somacount FCM, Bentley Instruments, Chaska, MN). Milk samples were tempered at 39 to $40^{\circ} \mathrm{C}$ before analysis to facilitate homogenization of the sample. Somatic cell score was calculated using the following equation (National Mastitis Council, 1999):

$$
\mathrm{SCS}=\log (\mathrm{SCC} / 100) / 0.6931+3 .
$$

At the time of sampling, the teats were sprayed with a teat disinfectant, dried with a clean cloth, and the teat ends were cleaned with a cotton pad soaked in $70 \%$ isopropyl alcohol. Initial strippings of foremilk were discarded and milk was aseptically collected from both udder halves into a single sterile tube (composite sample) for bacterial culture. Each goat's unique identification number and tube number were recorded, and the samples were frozen at $-20^{\circ} \mathrm{C}$ until analysis.

\section{Bacterial Culture}

Aerobic bacteriological culture was performed after thawing the tubes at room temperature (approximately $22^{\circ} \mathrm{C}$ ). Approximately $10 \mu \mathrm{L}$ of milk was plated on Co- 
lumbia blood agar (CBA; Remel, Lenexa, KS) using a sterile cotton-tipped applicator, plates were incubated at $37^{\circ} \mathrm{C}$ for $24 \mathrm{~h}$ and at room temperature for a further $24 \mathrm{~h}$. The plates were evaluated for presence of colonies at 24 and $48 \mathrm{~h}$. Cultures with $\geq 1 \mathrm{cfu}(\sim 100 \mathrm{cfu} /$ $\mathrm{mL}$ ) at $48 \mathrm{~h}$ were considered positive. Colonies were initially identified based on morphology, Gram stain, and catalase and coagulase tests according to the NMC guidelines (National Mastitis Council, 2017). Catalasepositive, gram-positive cocci were presumptively identified as Staphylococcus spp. Individual milk samples that yielded a single staphylococcal colony morphology on CBA at $48 \mathrm{~h}$ were defined as a single colony-type IMI and were used in the final data analysis. Samples that yielded $\geq 1$ cfu each of 2 different colony types (e.g., differences in size, color, and hemolytic pattern of the colonies) were defined as mixed infections and were not included in the final data analysis. Likewise, cultures with 3 or more different colony types were considered contaminated and were eliminated from the final data analysis. Isolates from samples that yielded a single staphylococcal colony type were sub-cultured from the coagulase tube and stored in phosphate-buffered glycerol at $-80^{\circ} \mathrm{C}$. Isolates presumptively identified as belonging to a non-staphylococcal genus were identified based on phenotypic characteristics only.

\section{PCR Amplification and Gene Sequencing}

Lysates of presumptively identified staphylococci were prepared for PCR by mixing 2 to 3 colonies obtained in pure culture with $100 \mu \mathrm{L}$ of Tris-EDTA buffer in microcentrifuge tubes and stored at $-20^{\circ} \mathrm{C}$ until analysis. For the purpose of evaluating the association of different staphylococcal species with SCS or MY, only isolates from milk samples that yielded a single colony type were subjected to species-level identification. Polymerase chain reaction amplification and sequencing of $r p o B$ were performed first (Drancourt and Raoult, 2002). When amplification or sequencing with rpo $B$ was unsuccessful or did not meet the identification criteria (see below), amplification and sequencing of tuf was performed (Hwang et al., 2011), followed by 16S-rRNA if tuf was unsuccessful (Becker et al., 2004). The PCR products were purified using a PureLink PCR purification kit (Invitrogen Life Technologies, Carlsbad, CA) and submitted to the University of Missouri DNA Core Facility for DNA sequencing. Gene sequences were compared with the GenBank database using the nucleotide-BLAST algorithm (www.ncbi.nlm .nih.gov). Species identification was assigned with $r p o B$ if there was $\geq 97 \%$ similarity with one of the database sequences (Fry et al., 2014); for tuf, $\geq 98 \%$ similarity and $>0.8 \%$ separation from the next species (Hwang et al., 2011); and for $16 \mathrm{~S}, \geq 99 \%$ similarity and $>0.8 \%$ separation from the next species (Hwang et al., 2011).

\section{MALDI-TOF}

Each isolate was cultured from phosphate-buffered glycerol on CBA at $37^{\circ} \mathrm{C}$ for 18 to $24 \mathrm{~h}$. Representative colonies were spotted in duplicate by direct transfer to the MALDI target plate (Bruker Daltonics, Billerica, MA), overlaid with $0.7 \mu \mathrm{L}$ of $70 \%$ formic acid and allowed to dry, then overlaid with $1 \mu \mathrm{L}$ of matrix solution ( $\alpha$-cyano-4-hydroxycinnamic acid in $50 \%$ acetonitrile and $2.5 \%$ trifluoroacetic acid) and allowed to dry. Plates were run on a Microflex LT/SH mass spectrometer (Bruker Daltonics). Generated spectra were assigned a score based on similarity with spectra from the RUO Biotyper database (Bruker Daltonics). Isolates with a score of $\geq 2.0$ for a given species on at least one of the duplicates were considered adequately identified to the species level (Tomazi et al., 2014). Isolates not identified after initial screening were prepared using the ethanol/formic acid extraction method as previously described (Tomazi et al., 2014). Briefly, 2 to 3 colonies were mixed in $300 \mu \mathrm{L}$ of HPLC-grade water (Sigma-Aldrich, St. Louis, MO) to which $900 \mu \mathrm{L}$ of pure ethanol was added, the solution was spun, the supernatant removed, and the pellet allowed to dry. The pellet was then mixed with $5 \mu \mathrm{L}$ of $70 \%$ formic acid and $5 \mu \mathrm{L}$ of acetonitrile, spun, and $0.7 \mu \mathrm{L}$ of the bacterial extract supernatant was spotted on the MALDI plate and allowed to dry, then overlaid with $1 \mu \mathrm{L}$ of matrix solution and run as before. A score of $\geq 2.0$ was likewise used for species identification.

\section{Statistical Analysis}

Apparent prevalence was estimated as the proportion of goats with a positive culture among goats sampled, after exclusion of goats with a sample designated as contaminated. The typeability of each identification method was reported as the proportion of isolates assigned a species identification. Accuracy was reported as the proportion of isolates identified with MALDI-TOF for which the species identification assigned matched the species identification assigned by partial sequence analysis of a housekeeping gene. Staphylococcal isolates not identified by gene sequencing were excluded from the analyses.

Mixed linear models were built to evaluate the relationship between species-specific staphylococcal IMI, SCS, and MY. Goats with $S$. aureus IMI were considered as positive controls, goats with no growth were included as negative controls, and goats with non-staphylococcal IMI, mixed IMI, or a contaminated sample were treated 
Table 1. Parity, DIM, milk yield, SCC, and SCS for 831 of 874 goats $^{1}$

\begin{tabular}{lccccc}
\hline Parameter & Median & Mean & SD & Minimum & Maximum \\
\hline Parity & 2 & 1.9 & 0.8 & 1 & 5 \\
DIM & 248 & 265.9 & 153.4 & 3 & 1,295 \\
Milk yield $(\mathrm{kg} / \mathrm{d})$ & 1.5 & 1.8 & 0.9 & 0.9 & 9.1 \\
SCC $(\times 1,000$ cells $/ \mathrm{mL})$ & 1,300 & 1,842 & 1,611 & 50 & 7,880 \\
SCS & 6.7 & 6.6 & 1.4 & 2 & 9.3 \\
\hline
\end{tabular}

${ }^{1}$ Data were missing for 43 goats.

${ }^{2}$ Milk yield readings of less than $0.9 \mathrm{~kg}$ were reported by DHIA as $0.9 \mathrm{~kg}$.

as missing values. The first mixed linear model investigated the effect of species-specific staphylococcal IMI status on SCS, after adjusting for confounding by DIM and parity, and with pen identification as a random intercept. Normality and homoscedasticity of residuals were visually assessed. Sidak-Bonferroni adjustment was used for comparing IMI for each identified staphylococcal species to samples yielding no growth. A second mixed linear model was used to investigate the effect of staphylococcal IMI status on MY, after adjusting for confounding by DIM and parity, and again with pen as a random intercept. In both models, linearity of the relationship between DIM and the outcome variable was assessed using polynomial square and cubic terms. Statistically significant polynomial terms were kept in the model when the relationship was deemed to be nonlinear. All analyses were performed using SAS 9.4 (SAS Institute Inc., Cary, NC).

\section{RESULTS}

Nine hundred forty goats were sampled, but samples from 66 goats were excluded due to incorrect recording of the goats' identification numbers leaving 874 goats. Parity, DIM, and MY data were available for 831 of 874 goats and are presented in Table 1. Goat parity ranged from 1 to 5 , with $310(36.9 \%)$ goats of first parity and $524(63.1 \%)$ goats of parity 2 or greater. Median (range) DIM on the DHIA test day was 248 (3 to 1,295 d). Milk yield ranged from 0.9 to $9.1 \mathrm{~kg} / \mathrm{d}$. For MY, any test day reading of less than $0.9 \mathrm{~kg}$ was reported by DHIA as $0.9 \mathrm{~kg}$. For this reason, data from goats with a reported MY of $0.9 \mathrm{~kg}(\mathrm{n}=240)$ were considered as missing data in the statistical model evaluating MY.

Samples from 538 goats had no growth, 17 samples were contaminated, and an IMI based on detection of at least $1 \mathrm{cfu} /$ plate of a bacterium was detected in 319 goats. The apparent prevalence of staphylococcal IMI was $24.4 \%$ (95\% CI: 21.5, 27.2\%) for single colony-type IMI and $31.2 \%$ (95\% CI: 28.2, 34.3\%) when combining single and mixed staphylococci IMI (Table 2).

Seven S. aureus isolates and 206 NAS isolates from samples that yielded a single colony type were sub- jected to gene sequence analysis. The typeability by rpo $B$ gene sequence $(\mathrm{n}=213$ isolates $)$ was $82.2 \%(95 \%$ CI: $77,87.3 \%$ ). The typeability by tuf gene sequence (n $=38$ isolates) was $84.2 \%$ (95\% CI: $72.6,95.8 \%$ ). The typeability by $16 \mathrm{~S}$ ( $\mathrm{n}=6$ isolates) was $16.7 \%(95 \%$ CI: 0, 46.5\%). When combining methods, among the 213 staphylococcal isolates, species identification was successfully assigned to 208 isolates, resulting in an overall typeability of $97.7 \%$ (95\% CI: 95.6, 99.7\%). The species with the highest prevalence were Staphylococcus simulans (7.9\%, 95\% CI: 6.1, 9.7\%), Staphylococcus xylosus (3.5\%, 95\% CI: 2.3, 4.7\%), Staphylococcus caprae (3.6\%, 95\% CI: 2.4, 4.9\%), Staphylococcus chromogenes (2.9\%, 95\% CI: 1.8, 4\%), and Staphylococcus epidermidis $(2.2 \%, 95 \%$ CI: $1.2,3.2 \%$; Table 3$)$. Five of the 206 NAS isolates could not be identified by gene sequence analysis, 3 of which had high sequence similarity with Staphylococcus warneri and Staphylococcus pasteuri, but insufficient separation between species.

The overall typeability with MALDI-TOF was $84 \%$ (179/213; 95\% CI: 79.1, 89\%). The typeability of isolates using MALDI-TOF varied by species (Table 3). When a species identification was assigned with MALDI-TOF (score $\geq 2.0$ ), accuracy was $100 \%$, using partial gene sequence analysis as reference identification method.

Table 2. Composite milk culture results in 874 goats

\begin{tabular}{|c|c|}
\hline Culture result & $\begin{array}{c}\text { No. of } \\
\text { cultures (\%) }\end{array}$ \\
\hline No growth & $538(61.6)$ \\
\hline \multicolumn{2}{|c|}{ Non-aureus Staphylococcus spp. (NAS) } \\
\hline Single colony-type infection & $206(23.6)$ \\
\hline Mixed NAS infection ${ }^{1}$ & $60(6.9)$ \\
\hline Staphylococcus aureus & $7(0.8)$ \\
\hline Mixed infection $^{2}$ & $8(0.9)$ \\
\hline Corynebacterium spp. & $12(1.4)$ \\
\hline Bacillus spp. & $11(1.3)$ \\
\hline Streptococcus spp. & $9(1)$ \\
\hline Other unidentified species & $6(0.7)$ \\
\hline Contaminated & $17(1.9)$ \\
\hline Total & $874(100)$ \\
\hline
\end{tabular}

${ }^{1}$ Positive cultures with 2 different NAS colony types.

${ }^{2}$ Positive cultures with 2 different colony types, of which at least one is not NAS. 
Using a score threshold of $\geq 1.7$ instead of $\geq 2.0$ for species identification, the overall typeability would have increased to $99.1 \%$ (211/213; 95\% CI: $97.8,100 \%)$, but accuracy would have decreased to $98.1 \%$ (204/208; $95 \%$ CI: $96.2,99.9 \%$; 2 isolates identified as $S$. caprae by gene sequence analysis were identified by MALDI-TOF as Staphylococcus saccharolyticus and Staphylococcus capitis). Of the 5 isolates without sequence-based identification, 2 isolates were identified as $S$. warneri by MALDI-TOF with a score $\geq 2.0$.

On the DHIA test day, SCS of all goats ranged from 2 to 9.3. Seven hundred forty-six goats with either no growth or a single colony-type Staphylococcus spp. that were identified to the species level were eligible for inclusion in the model; however, 38 of these goats had missing SCC data, leaving 708 goats for final inclusion in the SCS model. The final mixed linear model with SCS as the dependent variable showed that the staphylococcal IMI status was significantly associated with SCS $(P<0.01)$ after adjusting for confounding by DIM and parity. After adjustment for multiple comparisons, SCS of $S$. chromogenes IMI was significantly higher than SCS of the negative control goats (Table 4).

Of 746 goats with either no growth or single colonytype staphylococci successfully identified at the species level, 251 goats had missing MY data and were excluded, leaving 495 goats in the MY statistical model. The final mixed linear model with MY as the dependent variable, after adjusting for confounding by DIM and parity, did not reveal a significant association between staphylococcal IMI status and MY $(P$-value $=0.61)$. Although Staphylococcus lentus was associated with a clinically important variation in milk production (1.08 $\mathrm{kg} / \mathrm{d}$ less than negative controls), none of the estimates were statistically different (Table 5). Notably, despite data transformations to improve the model, assumption of homoscedasticity of residuals could not be met, and conclusions from this model should thus be interpreted with caution (i.e., the reported $P$-values and 95\% CI may be larger or smaller than the true frequentist values).

\section{DISCUSSION}

The goat-level prevalence of staphylococcal IMI (single and mixed) in the herd from the study presented here was estimated to be $31.2 \%$, which is similar to goat-level IMI prevalence ranges of 20 to $47 \%$ reported in previous studies (Contreras et al., 2003). It must be kept in mind that milk culture is an imperfect test, and thus the estimated prevalence may be different from the true prevalence. Similarly, in the present study, IMI was defined based on at least $\sim 100 \mathrm{cfu} / \mathrm{mL}$ on culture, whereas thresholds of $\geq 100, \geq 200, \geq 250$, or $\geq 500 \mathrm{cfu} /$

Table 3. Typeability of staphylococcal isolates using PCR amplification and partial gene sequencing of rpoB, tuf, and 16S rRNA, and MALDITOF MS

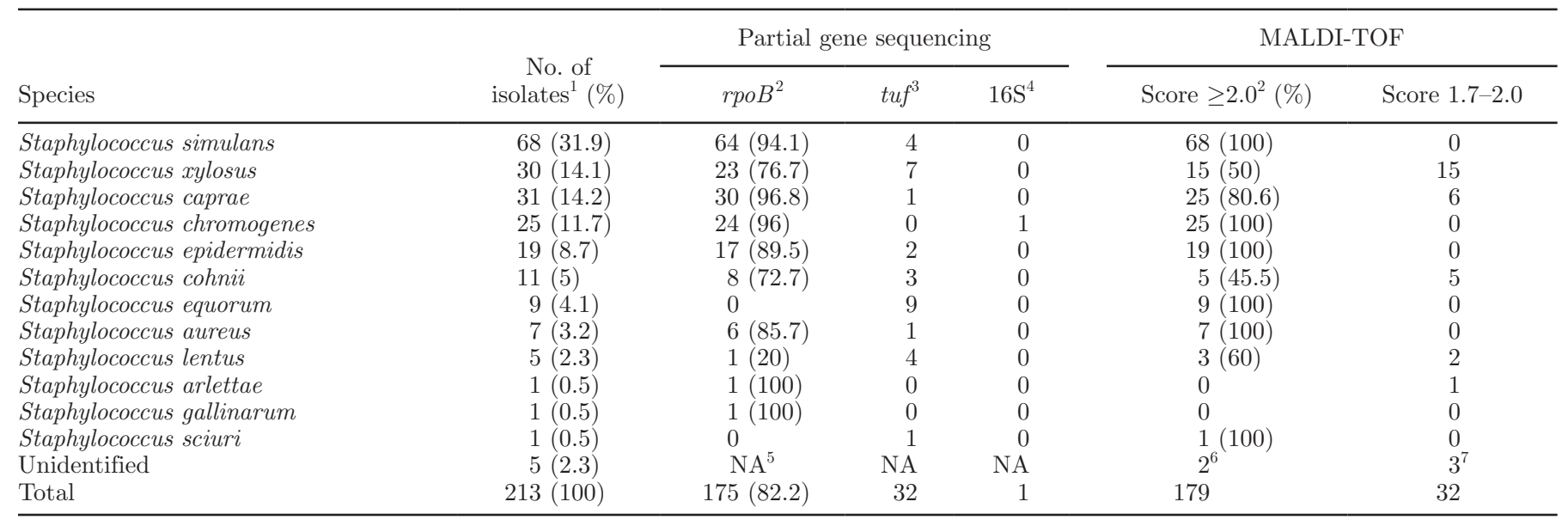

${ }^{1}$ Parenthetical data represent the proportion of a given species isolated among all staphylococci (within column).

${ }^{2}$ Parenthetical data represent the proportion of species-specific isolates identified (within row); for example, 64/68 $=94.1 \%$ of $S$. simulans were identified by $r$ ro $B$, and $68 / 68=100 \%$ were identified with MALDI-TOF.

${ }^{3}$ Only isolates not identified with $r p o B$ sequence analysis were subjected to tuf sequence analysis.

${ }^{4}$ Only isolates not identified with $r p o B$ or tuf sequence analysis were subjected to $16 \mathrm{~S}$ rRNA sequence analysis.

${ }^{5} \mathrm{NA}=$ not applicable.

${ }^{6}$ Isolates were identified as Staphylococcus warneri, but gene sequence homology did not meet the defined diagnostic threshold.

${ }^{7}$ Isolates were identified as $S$. warneri $(\mathrm{n}=1)$ and $S$. simulans $(\mathrm{n}=2)$, but gene sequence homology did not meet the defined diagnostic threshold. 
Table 4. Mixed linear model evaluating the association between composite milk culture result and SCS, and LSM estimates and 95\% CI of SCS according to IMI status, adjusted for confounding by DIM and parity, based on observations from 708 goats

\begin{tabular}{|c|c|c|c|c|c|}
\hline Effect & Estimate & $\mathrm{SE}$ & $P$-value ${ }^{1}$ & $\mathrm{LSM}^{2}$ & $95 \% \mathrm{CI}^{2}$ \\
\hline Intercept $^{3}$ & 5.98 & 0.14 & $<0.01$ & & \\
\hline Staphylococcal IMI status & & & $<0.01^{4}$ & & \\
\hline Staphylococcus xylosus & 0.17 & 0.31 & 0.59 & 6.64 & $6.03-7.24$ \\
\hline Staphylococcus simulans & 0.51 & 0.21 & 0.01 & 6.98 & $6.6-7.36$ \\
\hline Staphylococcus sciuri & 0.58 & 1.31 & 0.66 & 7.05 & $4.47-9.63$ \\
\hline Staphylococcus lentus & -0.34 & 0.66 & 0.61 & 6.13 & $4.84-7.42$ \\
\hline Staphylococcus gallinarum & 0.56 & 1.31 & 0.67 & 7.03 & $4.45-9.62$ \\
\hline Staphylococcus equorum & -0.05 & 0.36 & 0.9 & 6.42 & $5.71-7.12$ \\
\hline Staphylococcus epidermidis & 0.15 & 0.32 & 0.63 & 6.62 & $6.01-7.23$ \\
\hline Staphylococcus cohnii & 0.7 & 0.44 & 0.11 & 7.17 & $6.31-8.02$ \\
\hline Staphylococcus chromogenes & 1.3 & 0.28 & $<0.01$ & $7.77^{5}$ & $7.24-8.29$ \\
\hline Staphylococcus caprae & 0.18 & 0.27 & 0.5 & 6.65 & $6.14-7.16$ \\
\hline Staphylococcus arlettae & 1.47 & 0.62 & 0.02 & 7.94 & $6.73-9.15$ \\
\hline Staphylococcus aureus & 1.33 & 0.5 & 0.01 & 7.79 & $6.82-8.77$ \\
\hline No growth & Reference & - & - & 6.47 & $6.33-6.6$ \\
\hline Parity $^{6}$ & 0.29 & 0.06 & $<0.01$ & & \\
\hline $\mathrm{DIM}^{6}$ & 0.0002 & 0.0002 & 0.23 & & \\
\hline
\end{tabular}

${ }^{1}$ After Sidak-Bonferroni adjustment for multiple comparisons, significance was set at $P<0.004$.

${ }^{2}$ Least squares means estimates and $95 \%$ CI of the SCS of goats with a given IMI status were computed using results from the mixed model. Because reference categories in the model were parity 1 and DIM $=1$, these estimates represent SCS for a goat with these values. For a goat of parity 2, 0.29 can be added to the estimate; for a goat at 100 DIM, 0.02 (i.e., $100 \times 0.0002$ ) can be added.

${ }^{3}$ Somatic cell score for a goat of parity 1 , at kidding, with a negative milk culture.

${ }^{4}$ Joint $P$-value.

${ }^{5}$ LSM linear SCC significantly different from samples with no growth, after adjustment for multiple comparisons.

${ }^{6}$ Variables included as confounding variables.

Table 5. Mixed linear model evaluating the association between composite milk culture result and test-day milk production $(\mathrm{kg} / \mathrm{d})$, and LSM estimates and $95 \%$ CI for milk production $(\mathrm{kg} / \mathrm{d})$ according to IMI status, adjusted for confounding by DIM and parity, based on observations from 495 goats

\begin{tabular}{llcccc}
\hline Effect & Estimate & SE & $P_{\text {-value }}{ }^{1}$ & LSM $^{2}$ & $95 \%$ CI $^{2}$ \\
\hline Intercept $^{3}$ & 2.45 & 0.14 & $<0.01$ & & \\
Staphylococcal IMI status & & & $0.46^{4}$ & & \\
$\quad$ Staphylococcus xylosus & -0.07 & 0.22 & 0.76 & 2.04 & $1.62-2.46$ \\
Staphylococcus lentus & -1.08 & 0.48 & 0.03 & 1.02 & $0.08-1.97$ \\
Staphylococcus chromogenes & -0.04 & 0.25 & 0.86 & 2.06 & $1.58-2.55$ \\
Staphylococcus caprae & 0.01 & 0.19 & 0.95 & 2.12 & $1.76-2.48$ \\
Staphylococcus simulans & 0.09 & 0.14 & 0.52 & 2.2 & $1.94-2.45$ \\
Staphylococcus epidermidis & 0.29 & 0.23 & 0.22 & 2.4 & $1.94-2.85$ \\
Staphylococcus equorum & 0.30 & 0.34 & 0.37 & 2.41 & $1.75-3.07$ \\
Staphylococcus cohnii & -0.23 & 0.32 & 0.46 & 1.87 & $1.25-2.5$ \\
Staphylococcus sciuri & -0.2 & 0.82 & 0.81 & 1.91 & $0.29-3.52$ \\
Staphylococcus arlettae & 0.52 & 0.81 & 0.52 & 2.63 & $1.04-4.22$ \\
Staphylococcus aureus & 0.09 & 0.41 & 0.83 & 2.19 & $1.39-3$ \\
No growth $_{\text {Parity }}^{5}$ & Reference & - & - & 2.11 & $2.02-2.2$ \\
DIM $^{5}$ & -0.04 & 0.05 & 0.45 & & \\
DIM squared $^{5}$ & -0.001 & 0.0004 & $<0.01$ & & \\
I $^{5}$ & $1.61 \times 10^{-6}$ & 0 & $<0.01$ & & \\
\hline
\end{tabular}

${ }^{1}$ After Sidak-Bonferroni adjustment for multiple comparisons, significance was set at $P<0.005$. None of the goats infected with a staphylococcal species had a significantly different milk yield from goats with no growth, after adjustment for multiple comparisons.

${ }^{2}$ Least squares means estimates and $95 \%$ CI of the milk yield of goats with a given IMI status were computed using results from the mixed model. Because reference categories in the model were parity 1 and DIM $=1$, these estimates represent milk yield for a goat with these values. For a goat of parity 2, 0.04 can be subtracted from the estimate; for a goat at 100 DIM, 0.0839 (i.e., $100 \times-0.001+100^{2} \times 1.61 \times 10^{-6}$ ) can be subtracted. ${ }^{3}$ Milk production $(\mathrm{kg} / \mathrm{d})$ for a goat of parity 1 , at kidding, with negative milk culture.

${ }^{4}$ Joint $P$-value.

${ }^{5}$ Variables included as confounding variables. 
$\mathrm{mL}$ have been used by others (Contreras et al., 1997; Moroni et al., 2005a; Koop et al., 2012b; McDougall et al., 2014). Additional studies are needed to provide estimates of diagnostic performance for milk culture, and optimal definition threshold for the diagnosis of IMI in goats.

A total of 12 staphylococcal species were identified from goats having a single colony-type isolated from a composite milk sample. The most common species, $S$. simulans, S. xylosus, S. caprae, S. chromogenes, and $S$. epidermidis, were among the most common species in previous reports, although their relative prevalence varies between herds and studies (Contreras et al., 1995; Moroni et al., 2005b; Koop et al., 2012b). Other than a suspected relationship between postmilking teat dipping and the prevalence of $S$. epidermidis (Moroni et al., 2005a), there is a paucity of data on NAS speciesspecific risk factors explaining variations in the relative prevalence of NAS species between herds. Staphylococcus aureus isolates represented $3.3 \%$ (7/213) of staphylococcal isolates from single colony-type staphylococcal IMI, which is on the lower side of the previously reported range of 4 to $24 \%$ (Contreras et al., 2003).

The typeability of successive gene sequencing $(97.7 \%)$ was similar to the typeability of successive sequencing of rpoB, hsp60, $16 \mathrm{~S}$ rRNA, and tuf $(98.6 \%)$ reported for NAS isolates of cow milk origin (Supré et al., 2009). On the other hand, the typeability of $r p o B$ sequencing only $(82.2 \%)$ was lower than that reported for NAS isolates of cow milk origin (Supré et al., 2009). This could be attributed to the different species distribution of NAS isolates included in the typeability determination between the 2 studies. The difference in typeability could also be at least partially explained by differences between NAS strains of different host-species origin, and that NAS strains of caprine origin may have been poorly represented in the GenBank database relative to staphylococci originating from other mammalian species. The typeability of tuf sequencing was $84.2 \%$, which was similar to that of rpoB, but this result may be biased by the fact that this method of speciation was performed on a small subset of isolates that could not be identified by rроB sequence analysis. Due to its lower discriminatory power for NAS isolates (Hwang et al., 2011), 16S rRNA sequence analysis was performed only when rроB and tuf sequence analysis failed to identify an isolate.

Using a score of $\geq 2.0$, the typeability of MALDI-TOF was $84 \%$, which was higher than $63.7 \%$ reported by Cameron et al. (2017) on cows' isolates, but lower than $95.4 \%$ reported by Tomazi et al. (2014). Identification by MALDI-TOF in the present study was performed in 2 steps, using first the direct transfer method with formic acid, then complemented by the ethanol/formic acid extraction method as used by Tomazi et al. (2014). This latter protocol causes bacterial lysis and results in improved spectrum quality, therefore improving typeability (Cameron et al., 2017). This may explain why the typeability reported here using a 2-step identification protocol was superior to that of direct transfer only reported by Cameron et al. (2017). Staphylococcal species-specific differences in typeability observed in the present study have also been reported for human and bovine NAS isolates (Richter et al., 2012; Cameron et al., 2017). It is noteworthy that Staphylococcus cohnii had a low typeability in the previous and current studies, whereas S. xylosus isolates of human origin had a typeability of $100 \%$ (Richter et al., 2012), compared with isolates of bovine and caprine origin with typeabilities of 59 to $62 \%$ (Cameron et al., 2017, 2018) and $50 \%$ (present study), respectively. Like other molecular identification methods, due to within species variation, typeability of MALDI-TOF is influenced by the strains used to build the database. This can decrease the performance of MALDI-TOF, especially when identifying isolates from a different host species. To circumvent this problem, a custom library can be built to complement the commercial database, and this approach has been reported to significantly improve typeability (Cameron et al., 2017); however, this was not performed in the present study. Using a score of $\geq 1.7$ for species identification also resulted in improved typeability, while minimally decreasing accuracy.

In the study reported here, staphylococcal IMI status was significantly associated with SCS, after adjusting for confounding by DIM and parity, which was in agreement with previous reports on goat-level (Wilson et al., 1995) and half-level IMI (Leitner et al., 2004b; Moroni et al., 2005b; Koop et al., 2012b). Goats with S. chromogenes IMI had a significantly higher SCS than goats with no growth. Similar findings were previously reported for S. simulans, S. aureus, S. caprae, and $S$. epidermidis (Deinhofer and Pernthaner, 1995; Moroni et al., 2005a). An increased SCC also was previously reported with $S$. chromogenes, although the number of isolates in this prior study was too small for statistical analysis (Deinhofer and Pernthaner, 1995).

This study has some limitations. Between-herd variation in staphylococcal species prevalence and associations with the measured dependent variables could not be evaluated in the present study due to use of a single herd. The typeability of MALDI-TOF for identification of the staphylococcal strains obtained from this herd may not be representative of staphylococcal strains from other goat herds, although more recent work by our research group has shown high strain diversity 
within NAS species from this herd, as well as high typeability of MALDI-TOF for strains from other herds (V. Bernier Gosselin, unpublished data). Although the herd was large, yielding a large within-herd sample size, as with any observational study, approximately half of the staphylococcal species (7/12 when including $S$. aureus) were represented by fewer than 10 goats each. Hence, estimates of the association of IMI with low prevalence species on the measured dependent variables could be affected by minimal replication within the data set. Additionally, both the culture result (composite milk sample) and SCS were measured at the goat level, and thus it could not be determined whether an IMI was present in one or both udder halves. If an IMI was present and associated with increased SCC in one half, a dilution effect by the unaffected, lower SCC half might have decreased the magnitude of the difference detected at the goat level. Future studies will evaluate these factors at the udder-half level.

The present study did not find an association between culture result and MY. From the literature, the association between NAS species IMI and MY is equivocal. A negative association between IMI and MY was reported at the half level (Leitner et al., 2004a), whereas another study reported a positive association between $S$. caprae IMI and MY at the goat level (Koop et al., 2012b), and others reported no association (Moroni et al., 2005a; Koop et al., 2010). The use of various study designs and statistical models, including whether infection status and MY were analyzed at the goat level or half level, and NAS species analyzed as a group or at the species level, may explain some of this discrepancy. Koop et al. (2010) hypothesized that a unilateral IMI could cause a decrease in milk production from the affected half, which would be compensated by the contralateral half and therefore undetected when MY was measured at the goat level. Additionally, when evaluating the effect of different NAS species, the small number of IMI caused by some species may negatively affect statistical power (Koop et al., 2012b).

In conclusion, the study of differences between staphylococcal species requires accurate and reliable species identification. As a more rapid and cost-effective method, MALDI-TOF could be used as an initial identification method, along with the development of a custom library to improve typeability, and complemented by other molecular methods such as gene sequencing when necessary. Further investigation is warranted regarding the interaction of IMI and duration of IMI as well as the interacting or confounding effect of caprine arthritis-encephalitis virus infection on the association of staphylococcal species IMI with SCS and MY.

\section{ACKNOWLEDGMENTS}

The authors thank University of Missouri student Emily Quas for her contribution to the identification of bacterial isolates. This study was supported by the USDA National Institute of Food and Agriculture (Washington, DC; Project No. AH1669447616, 20142017), and a grant from the Pi Chapter of the Phi Zeta Veterinary Honor Society (Columbia, MO).

\section{REFERENCES}

Becker, K., D. Harmsen, A. Mellmann, C. Meier, P. Schumann, G. Peters, and C. von Eiff. 2004. Development and evaluation of a quality-controlled ribosomal sequence database for $16 \mathrm{~S}$ ribosomal DNA-based identification of Staphylococcus species. J. Clin. Microbiol. 42:4988-4995.

Bergonier, D., R. de Cremoux, R. Rupp, G. Lagriffoul, and X. Berthelot. 2003. Mastitis of dairy small ruminants. Vet. Res. 34:689-716.

Cameron, M., H. W. Barkema, J. De Buck, S. De Vliegher, M. Chaffer, J. Lewis, and G. P. Keefe. 2017. Identification of bovine-associated coagulase-negative staphylococci by matrix-assisted laser desorption/ionization time-of-flight mass spectrometry using a direct transfer protocol. J. Dairy Sci. 100:2137-2147.

Cameron, M., J. Perry, J. R. Middleton, M. Chaffer, J. Lewis, and G. P. Keefe. 2018. Short communication: Evaluation of MALDI-TOF mass spectrometry and a custom reference spectra expanded database for the identification of bovine-associated coagulase-negative staphylococci. J. Dairy Sci. 101:590-595. https://doi.org/10.3168/ jds.2017-13226.

Contreras, A., J. C. Corrales, A. Sanchez, and D. Sierra. 1997. Persistence of subclinical intramammary pathogens in goats throughout lactation. J. Dairy Sci. 80:2815-2819.

Contreras, A., J. C. Corrales, D. Sierra, and J. Marco. 1995. Prevalence and aetiology of non-clinical intramammary infection in Murciano-Granadina goats. Small Rumin. Res. 17:71-78.

Contreras, A., C. Luengo, A. Sánchez, and J. C. Corrales. 2003. The role of intramammary pathogens in dairy goats. Livest. Prod. Sci. $79: 273-283$.

Deinhofer, M., and A. Pernthaner. 1995. Staphylococcus spp. as mastitis-related pathogens in goat milk. Vet. Microbiol. 43:161-166.

Drancourt, M., and D. Raoult. 2002. rpoB gene sequence-based identification of Staphylococcus species. J. Clin. Microbiol. 40:1333-1338.

Fry, P. R., J. R. Middleton, S. Dufour, J. Perry, D. Scholl, and I. Dohoo. 2014. Association of coagulase-negative staphylococcal species, mammary quarter milk somatic cell count, and persistence of intramammary infection in dairy cattle. J. Dairy Sci. 97:4876-4885.

Hwang, S. M., M. S. Kim, K. U. Park, J. Song, and E. C. Kim. 2011. tuf gene sequence analysis has greater discriminatory power than $16 \mathrm{~S}$ rRNA sequence analysis in identification of clinical isolates of coagulase-negative staphylococci. J. Clin. Microbiol. 49:4142-4149.

Koop, G., A. De Visscher, C. A. Collar, D. A. Bacon, E. A. Maga J. D. Murray, K. Supre, S. De Vliegher, F. Haesebrouck, J. D. Rowe, M. Nielen, and T. van Werven. 2012a. Short communication: Identification of coagulase-negative staphylococcus species from goat milk with the API Staph identification test and with transfer RNA-intergenic spacer PCR combined with capillary electrophoresis. J. Dairy Sci. 95:7200-7205.

Koop, G., S. De Vliegher, A. De Visscher, K. Supre, F. Haesebrouck, M. Nielen, and T. van Werven. 2012b. Differences between coagulase-negative Staphylococcus species in persistence and in effect on somatic cell count and milk yield in dairy goats. J. Dairy Sci. 95:5075-5084. 
Koop, G., T. van Werven, H. J. Schuiling, and M. Nielen. 2010. The effect of subclinical mastitis on milk yield in dairy goats. J. Dairy Sci. 93:5809-5817.

Leitner, G., U. Merin, and N. Silanikove. 2004a. Changes in milk composition as affected by subclinical mastitis in goats. J. Dairy Sci. $87: 1719-1726$.

Leitner, G., U. Merin, N. Silanikove, E. Ezra, M. Chaffer, N. Gollop, M. Winkler, A. Glickman, and A. Saran. 2004b. Effect of subclinical intramammary infection on somatic cell counts, NAGase activity and gross composition of goats milk. J. Dairy Res. 71:311-315.

McDougall, S., D. Malcolm, and C. Prosser. 2014. Prevalence and incidence of intramammary infections in lactating dairy goats. $\mathrm{N}$. Z. Vet. J. 62:136-145.

McDougall, S., K. Supré, S. De Vliegher, F. Haesebrouck, H. Hussein, L. Clausen, and C. Prosser. 2010. Diagnosis and treatment of subclinical mastitis in early lactation in dairy goats. J. Dairy Sci. 93:4710-4721.

Moroni, P., G. Pisoni, M. Antonini, G. Ruffo, S. Carli, G. Varisco, and P. Boettcher. 2005a. Subclinical mastitis and antimicrobial susceptibility of Staphylococcus caprae and Staphylococcus epidermidis isolated from two Italian goat herds. J. Dairy Sci. 88:1694-1704.

Moroni, P., G. Pisoni, G. Ruffo, and P. J. Boettcher. 2005b. Risk factors for intramammary infections and relationship with somaticcell counts in Italian dairy goats. Prev. Vet. Med. 69:163-173.

National Mastitis Council. 1999. Laboratory Handbook on Bovine Mastitis. Rev. ed. National Mastitis Council, Madison, WI.

National Mastitis Council. 2017. Laboratory Handbook on Bovine Mastitis. 3rd ed. National Mastitis Council, New Prague, MN.
Onni, T., A. Vidili, E. Bandino, G. Marogna, S. Schianchi, and S. Tola. 2012. Identification of coagulase-negative staphylococci isolated from caprine milk samples by PCR-RFLP of groEL gene. Small Rumin. Res. 104:185-190.

Paape, M. J., and A. V. Capuco. 1997. Cellular defense mechanisms in the udder and lactation of goats. J. Anim. Sci. 75:556-565.

Richter, C., S. Hollstein, J. Woloszyn, M. Kaase, S. G. Gatermann, and F. Szabados. 2012. Evaluation of species-specific score cut-off values for various Staphylococcus species using a MALDI Biotyperbased identification. J. Med. Microbiol. 61:1409-1416.

Supré, K., S. De Vliegher, O. C. Sampimon, R. N. Zadoks, M. Vaneechoutte, M. Baele, E. De Graef, S. Piepers, and F. Haesebrouck. 2009. Technical note: use of transfer RNA-intergenic spacer PCR combined with capillary electrophoresis to identify coagulase-negative Staphylococcus species originating from bovine milk and teat apices. J. Dairy Sci. 92:3204-3210.

Tomazi, T., J. L. Goncalves, J. R. Barreiro, P. A. de Campos Braga, L. F. Prada e Silva, M. N. Eberlin, and M. V. dos Santos. 2014. Identification of coagulase-negative staphylococci from bovine intramammary infection by matrix-assisted laser desorption ionizationtime of flight mass spectrometry. J. Clin. Microbiol. 52:1658-1663.

Wilson, D. J., K. N. Stewart, and P. M. Sears. 1995. Effects of stage of lactation, production, parity and season on somatic cell counts in infected and uninfected dairy goats. Small Rumin. Res. 16:165169.

Zadoks, R. N., and J. L. Watts. 2009. Species identification of coagulase-negative staphylococci: Genotyping is superior to phenotyping. Vet. Microbiol. 134:20-28. 